\title{
Effects of Bacterial ACC Deaminase on Brassica napus Gene Expression
}

\author{
Jennifer C. Stearns, Owen Z. Woody, Brendan J. McConkey, and Bernard R. Glick \\ Department of Biology, University of Waterloo, Waterloo, Ontario N2L 3G1, Canada
}

Submitted 17 August 2011. Accepted 5 January 2012.

\begin{abstract}
Plants in association with plant growth-promoting rhizobacteria can benefit from lower plant ethylene levels through the action of the bacterial enzyme 1-aminocyclopropane-1carboxylic acid (ACC) deaminase. This enzyme cleaves the immediate biosynthetic precursor of ethylene, ACC. Ethylene is responsible for many aspects of plant growth and development but, under stressful conditions, it exacerbates stress symptoms. The ACC deaminase-containing bacterium Pseudomonas putida UW4 is a potent plant growth-promoting strain and, as such, was used to elaborate the detailed role of bacterial ACC deaminase in Brassica napus (canola) plant growth promotion. Transcriptional changes in bacterially treated canola plants were investigated with the use of an Arabidopsis thaliana oligonucleotide microarray. A heterologous approach was necessary because there are few tools available at present to measure global expression changes in nonmodel organisms, specifically with the sensitivity of microarrays. The results indicate that the transcription of genes involved in plant hormone regulation, secondary metabolism, and stress response was altered in plants by the presence of the bacterium, whereas the upregulation of genes for auxin response factors and the downregulation of stress response genes was observed only in the presence of bacterial ACC deaminase. These results support the suggestion that there is a direct link between ethylene and the auxin response, which has been suggested from physiological studies, and provide more evidence for the stress-reducing benefits of ACC deaminase-expressing plant growth-promoting bacteria.
\end{abstract}

Plant growth-promoting rhizobacteria (PGPR) are free-living soil bacteria that are commonly found in close proximity to plant roots. They are widespread in the environment and have been shown to improve plant fitness in a variety of situations, including forest regeneration, crop yield improvement, and phytoremediation (Glick 2003; Kloepper et al. 1989; Reed and Glick 2004). Some of the mechanisms involved in plant growth promotion by these bacteria include the production of phytohormones and iron-sequestering siderophores which are of direct use to the plant, the provision of nutrients such as phosphorous and nitrogen, and the lowering of plant ethylene levels through the action of the bacterial enzyme 1-aminocy-

Current address of J. C. Stearns: Department of Medicine, McMaster University, Hamilton, Ontario L8S 4K1, Canada.

Corresponding author: J. C. Stearns;

E-mail: jennifer.c.stearns@gmail.com

* The $\boldsymbol{e}$-Xtra logo stands for "electronic extra" and indicates four supplementary tables are published online. clopropane-1-carboxylate (ACC) deaminase (Glick et al. 1999). Plants also benefit from PGPR colonization that induces biocontrol of pathogenic organisms. There are several mechanisms by which this proceeds, including bacterial production of antibiotics and antifungal metabolites; competition between the beneficial bacteria and pathogens for nutrients and niches along the plant tissues; and induced systemic resistance (ISR), where local PGPR colonization of root tissues leads to systemic plant defense signaling that deters pathogen action (Lugtenberg and Kamilova 2009).

PGPR in close proximity to plant root cells are able to take up small molecules such as sugars and amino acids, known as plant exudates, released into the rhizosphere by either plant roots or seed (Walker et al. 2003). Bacterial ACC deaminase catalyzes the cleavage of the direct precursor to ethylene biosynthesis, ACC, which is secreted from the plant cell and taken up by bacteria in the rhizosphere. Thus, bacteria bound to the plant root or seed and expressing ACC deaminase act as a sink for plant ACC, thereby lowering the concentration of this metabolite within the plant (Penrose et al. 2001).

Ethylene is a gaseous plant hormone that regulates many physiological processes, including germination, root development, flower and fruit development, senescence, and abscission (Abeles et al. 1992), and also plays a key role in cell elongation, cell death, biotic and abiotic stress, nodulation, and systemic resistance to pathogens (Bleecker and Kende 2000). Stress, in particular, has been shown to cause increased ethylene production (called stress ethylene) in plants and negatively affects plant fitness (Glick et al. 2007; Hyodo 1991). PGPR expressing a bacterial ACC deaminase gene have been shown to improve plant health and growth in the presence of metals, flooding, drought, organic contaminants, salt, arsenate, and pathogens (Glick 2004).

Brassica napus (canola) is an important crop plant and has previously been studied in conjunction with the plant growthpromoting bacterium Pseudomonas putida UW4, which expresses a high level of ACC deaminase, in successful laboratory and field trials. In the absence of stress, this strain increased plant root length by 1.3 - to 1.8 -fold over uninoculated plants (Hontzeas et al. 2004; Li et al. 2000). Also, under low flooding stress or high salt and cold conditions, the addition of $P$. putida UW4 enhanced canola shoot dry biomass 1.4 and 4 times over uninoculated plants, respectively (Cheng et al. 2007; Farwell et al. 2007). In this study, a heterologous approach involving an Arabidopsis thaliana oligonucleotide microarray was used to study canola transcriptional responses to colonization by $P$. putida UW4 (both the ACC deaminase-expressing wild-type strain and an ACC deaminase-minus mutant strain). This heterologous method was further validated using real-time reversetranscriptase polymerase chain reaction (RT-PCR) and was shown to accurately reflect the overall changes in canola gene 
expression, adding a valuable tool for the study of nonmodel plants.

\section{RESULTS AND DISCUSSION}

The expression of many plant genes change as a result of bacterial inoculation with both

ACC deaminase-expressing and nonexpressing strains.

Canola (B. napus) seed were inoculated with either wild-type P. putida $\mathrm{UW} 4\left(\mathrm{ACD}^{+}\right)$, which naturally expresses $\mathrm{ACC}$ deaminase (Shah et al. 1998), or an ACC deaminase knockout mutant of the same strain $\left(\mathrm{ACD}^{-}\right)$( $\mathrm{Li}$ et al. 2000) and expression profiles of 6-day-old seedlings were compared with uninoculated control plants in a two-color microarray hybridization. Bacterial inoculation caused a profound impact on plant gene expression, where the presence of $P$. putida UW4 (either $\mathrm{ACD}^{+}$or $\mathrm{ACD}^{-}$) caused the following number of statistically significant expression changes: 965 in the shoots and 336 in the roots. The small amount of overlap between the lists of genes whose expression was changed suggests that responses were tissue specific with respect to shoots and roots. The subset of expression changes that differed between plants treated with the $\mathrm{ACD}^{+}$bacterial strain and the $\mathrm{ACD}^{-}$mutant bacteria strain were 559 in the shoots and 95 in the roots, indicating that inoculation of plants with bacteria expressing ACC deaminase caused altered plant responses at the transcriptional level. All of these statistically significant expression fold changes are presented in Supplementary Tables 1 through 4 . For the most part, those changes in plant gene expression that present patterns of interest are highlighted here.

\section{Expression profiles were similar for both bacterial strains,} although some important differences were apparent.

Co-expression relationships between plant genes in response to inoculation with $\mathrm{ACD}^{+}$and $\mathrm{ACD}^{-}$P. putida $\mathrm{UW} 4$ compared with uninoculated control tissues are presented in Figure 1. As expected, the expression patterns for shoot and root tissues were very different from one another. The number of significant expression changes and the magnitude of these changes were greater in shoot tissue, possibly due to some loss of root tip material during collection reducing the impact of transcriptional changes typically seen in this area of the root (Brady et al. 2007). Also, not surprisingly, the expression profiles of plant genes that occurred as a consequence of treatment with either $\mathrm{ACD}^{+}$or $\mathrm{ACD}^{-}$strains were very similar, with some subtle differences. In particular, three areas of interest are labeled in the cluster heat map (Fig. 1A).

Two groups of co-expressed genes (Fig. 1B and D) were either upregulated in the shoots of plants inoculated with the $\mathrm{ACD}^{-}$bacteria or downregulated in the shoots of plants treated with $\mathrm{ACD}^{+}$bacteria, and included many genes thought to be involved in, or induced by, plant stress (The Arabidopsis Information Resource). In a previous study of the same system, our lab saw the downregulation of two plant stress genes, a glycine-rich stress protein and a defense signaling pathway gene (Hontzeas et al. 2004). In order to gain more insight into this finding, the higher-sensitivity and greater-scope microarrays were used. Here, the list of stress-response genes included several genes encoding photosynthetic proteins, a UV-induced protein gene, a salicylic acid-mediated disease resistance gene, several heat-shock protein genes, a defense-related protein gene, several cytochrome $\mathrm{P} 450$ genes, glutathione $S$-transferase genes, a senescence-associated protein gene, a stress-inducible protein gene, and an iron superoxide dismutase gene.

Another group of genes (Fig. 1C) was upregulated in the shoots of plants inoculated with $\mathrm{ACD}^{+} P$. putida $\mathrm{UW} 4$ and included several auxin response factors (ARF), which are tran- scription factors known to be rapidly induced by active auxins (Hagen and Guilfoyle 2002). Eight different ARF genes were upregulated, including three members of the auxin/indole acetic acid (AUX/IAA) gene family (IAA1, AT4G14560; IAA5, AT1G15580; and IAA19, AT3G15540), four members of the small up RNA (SAUR) gene family (AT4G38860, AT3G03820, AT3G03830, and AT4G34770), and one auxin transport protein gene (PIN3, AT1G70940).

\section{Several plant metabolic pathway genes displayed altered} transcription in response to bacterial inoculation.

Lists of genes with statistically significant expression changes were grouped by metabolic function according to their annotation within the AraCyc database (Zhang et al. 2005), correlating gene expression changes with metabolic pathways for genes whose product catalyzes an enzymatic reaction. A summary of changes for which metabolic pathway assignments are available is presented in Table 1, with selected cases discussed below.

Within the phytohormone category, there was an upregulation in allene oxide synthase (an important part of the jasmonic acid biosynthesis pathway) in $\mathrm{ACD}^{-}$-treated plant shoots. Salicylic acid biosynthesis was downregulated in shoots of plants treated with both $\mathrm{ACD}^{+}$and $\mathrm{ACD}^{-}$bacteria whereas $\mathrm{ACC}$ oxidase was upregulated in those tissues. The increase in the expression of ACC oxidase transcripts in the presence of $P$. putida UW4 inoculation (both $\mathrm{ACD}^{-}$and $\mathrm{ACD}^{+}$) was surprising because the genes for this enzyme are thought to be developmentally regulated and expressed at low levels in vegetative tissues (Abeles et al. 1992). In the presence ACC deaminase-expressing $P$. putida UW4, the lower level of ACC was expected to cause a reduction in ACC oxidase activity in plant tissues (Madhaiyan et al. 2006). Because this PGPR strain has been shown to produce IAA ( $\mathrm{Li}$ et al. 2000), it is possible that there was an induction of ACC oxidase gene expression in the presence of bacterially produced IAA (which also turns on ACC synthase gene expression) that, in the absence of ACC deaminase, resulted in the increased accumulation of ACC in plant tissues.

Secondary metabolism was downregulated at the expression level for plants treated with both bacterial strains $\left(\mathrm{ACD}^{+}\right.$and $\mathrm{ACD}^{-}$P. putida UW4). Examples include members of the flavonoids (including anthocyanins, flavonols, and kaempferol glucoside), terpenoids (including carotenoids and geranyldiphosphate), the phytoalexin camalexin, glucosinolates, and phenylpropanoids.

Other changes of note in shoots of $\mathrm{ACD}^{+} P$. putida UW4-inoculated plants include altered expression of genes involved in nitrate and ammonia assimilation (downregulated) and lactose and sucrose degradation (upregulated).

\section{$B$. napus gene expression changes measured with an A. thaliana microarray were reproducibly measured with real-time RT-PCR.}

In order to confirm the ability of probes designed to $A$. thaliana genes on the microarray to report relevant $B$. napus transcript levels, real-time RT-PCR amplification of nine different $B$. napus genes was used for comparison. Due to the lack of genomic information for canola, an expressed-sequence tag (EST) library was queried for matches to the microarray probe sequences. Custom primers were designed to correspond to the region of each EST that would bind the probe sequences, and sequenced $B$. napus PCR products were aligned with both the expected Brassica EST sequences and with the A. thaliana reference sequence for each gene product. There were fewer than four nucleotide differences in all sequenced PCR products when compared with the Brassica EST sequences, which was expected for a within-genus comparison; and, in each case, the 


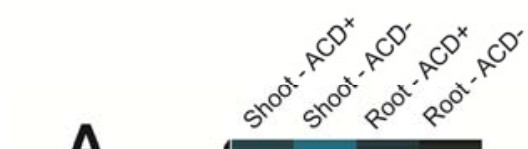

A
5.0
-5.0

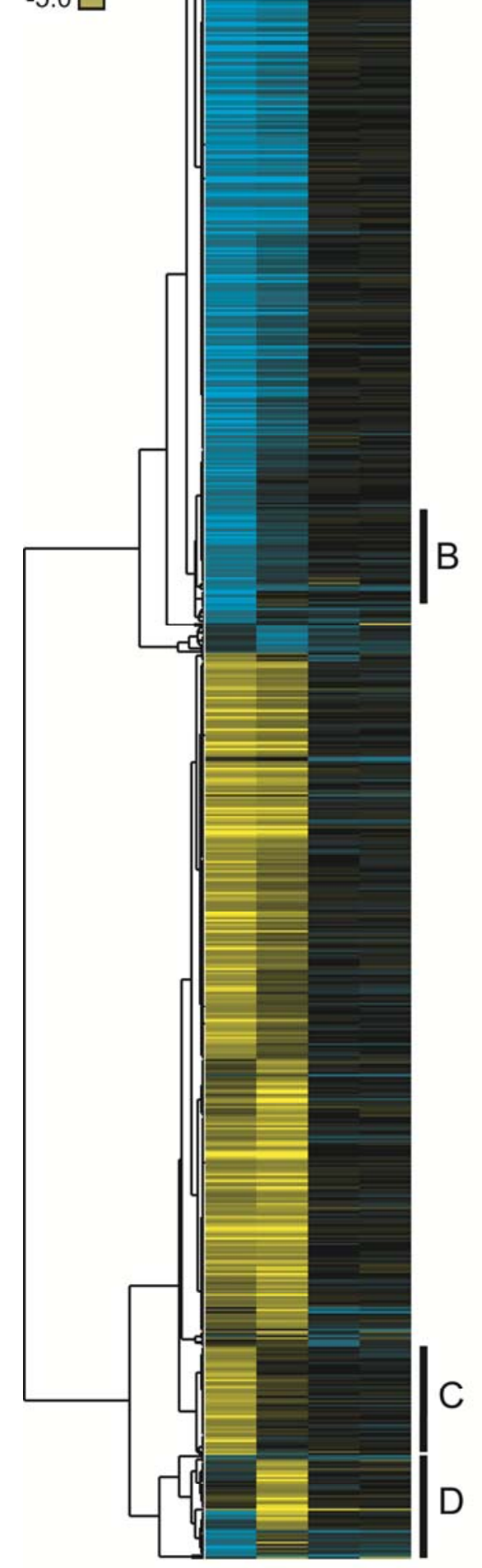

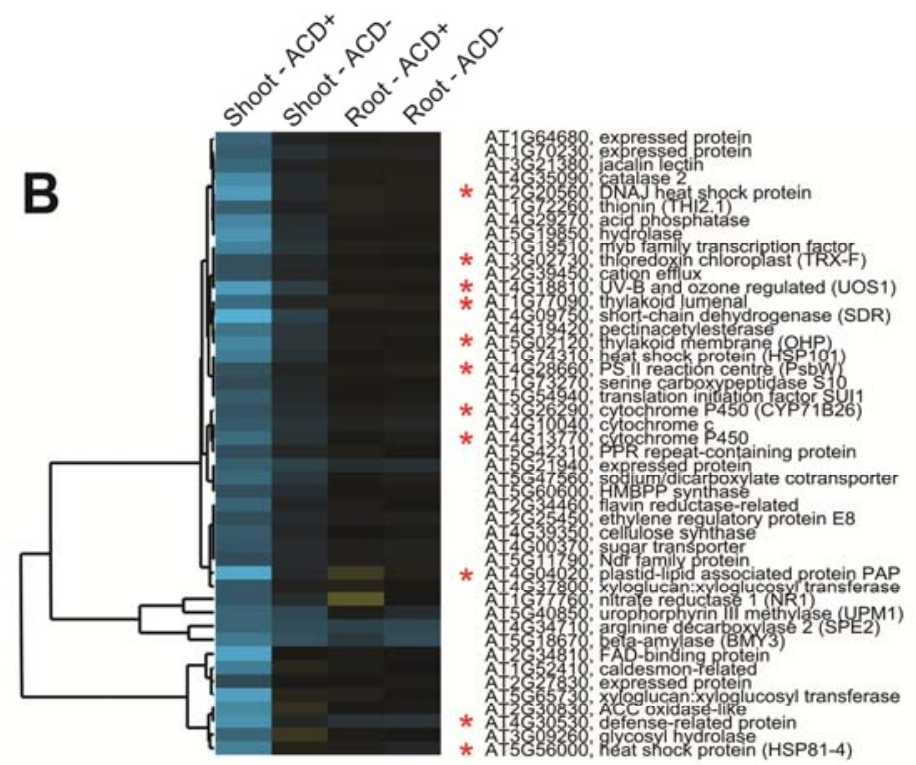

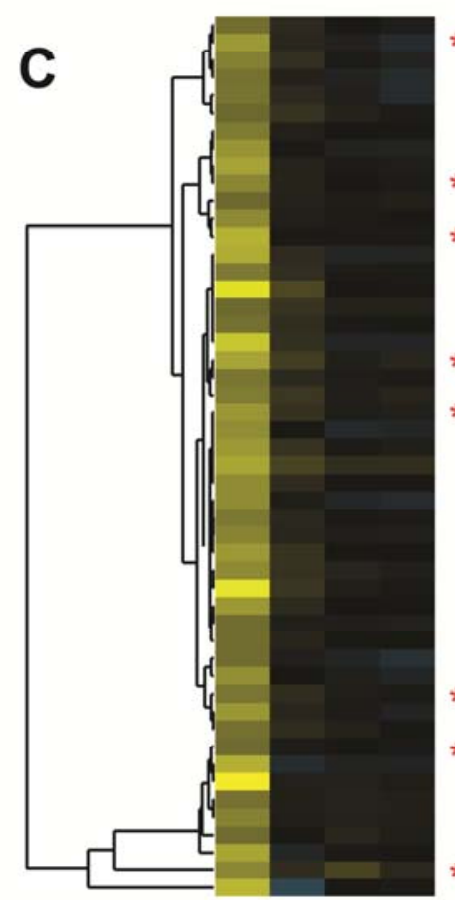

AT1G26210, expressed protein
AT1G70940, auxin transport (PIN3)
AT 155330 , arabinogalactan (AGP2

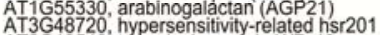

AT2G19540, transducin protein WD-40 repeat

A $5 \mathrm{G} 20110$, dynein light chain LCE

AT $3 G 04620$, expressed protein

AT2G15090, 'atty y acid elongase

AT2G27440, rac GTP ase activating

AT2G41820, leucine-rich repeat protein kinase

AT3G15540, auxin-responsive 19 (IAA19)

AT1611545, xyloglucan:xyloglucosyl tran serase AT1

AT3G51400, expressed protein

A. $\mathrm{G} 30200$, expressed protein

AT5G52920, pyruvate kinase
AT3G03820, auxin-responsive SAUR

AT3G03820, auxin-responsive SAUR
AT3G07490, calcium-binding protein

AT5G63810, beta-galactosidiase

AT3G03830, auxin-responsive SAUR

AT1G77330, ACC oxidase

AT4G32285, ENTH domain-containing protein

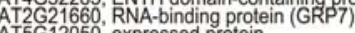

AT3G08030, expressed protein

AT 1G28530, expressed protein

AT5G41140, expressed protein

AT4G2020, 65450 Glycien-ich protein

AT 4 G3220, pectinesterase family protein

AT5 25460 expressed protein

AT5G63560, like hypersensitivity-related HSR201

A 548460 , fimbrin-like protent

AT3G58850, expressed protein AT4G30280, xylog ucan:xyloglucosyl transferase

AT5G62670, ATPase

AT1615580, auxin-responsive//AA-induced (IAA5)

AT G $3060990, \mathrm{SEC} 14$ cytosolic tactor $\mathrm{NPH}$

AT4G33720, pathogenesis-related

AT5G26160, expressed protein
AT3G21330, basic helix-loop-helix (bHLH) family

AT4G34770, auxin-responsive X10A

AT4G34770, auxin-responsive X10A
AT5G25190, ethylene-responsive element-binding

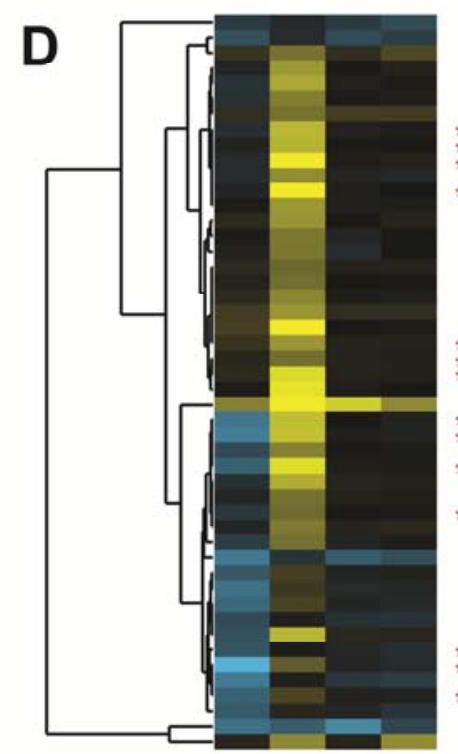

AT1676640, calmodulin-related

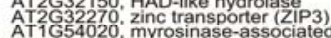

AT2643910, thiol methyytransferase

AT5G1880, sugar transporter similar to ERD 6

* AT1659860. heat shock protein (HSP 17.6A-Cl)

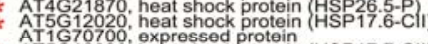

* AT5G1203, heat shoc procterin (HSP17.7-CIII)

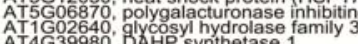

AT4G38810, calcium-binding protein

ATC

AT3G53800, armadilloroeta-catenin repeat

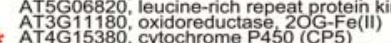

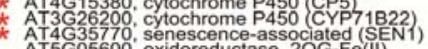

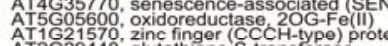

* AT2G2944, glutathione S-transferase (103-1A)

AT3G44870; SAM carboxyl methyltransferase

* AT3G46230, heat shock protelin (HSPP17.4.CA

* AT2G29670, expressed protein (HSP 100)

AT5G27380, glutathione synthetase (GSH2)

AT4G30550, glutathine amidotranseferase

AT3G16470, jacalin lectin protein

AT5658310, nucleotide pyrophosphatase

AT4G12400' stress-

* AT4G29710, 'nucleotide pyrophososphatase

AT4G29690, nucleotide pyrophosphatase
AT 3653420
AT 
nucleotide sequence identity between the chosen Brassica and A. thaliana transcripts was very high (78 to 90\%) (Table 2).

Expression values measured with real-time RT-PCR are presented in Figure 2A and correlated with those measured using oligonucleotide microarrays, with an $R^{2}=0.904$ (Fig. 2B). The genes chosen are of interest due to the role of their gene product in plant stress response and auxin signaling. Interestingly, microarray fold changes were consistently smaller than those measured with real-time RT-PCR, as illustrated by the appearance of the data points in relation to the $1: 1$ relationship line in Figure 2B. The increased magnitude of fold changes measured with real-time RT-PCR over microarray is evident from the fact that many of the positive fold changes appear above the line whereas many of the negative fold changes appear below it.

\section{Conclusions.}

Plant growth-promoting bacteria improve plant fitness in a variety of ways, including the lowering of plant ethylene levels via the action of the bacterial enzyme ACC deaminase. Bacteria that produce this enzyme have been shown to increase plant root length and biomass and reduce the symptoms of stress, including senescence, necrosis, and stunting, under a variety of conditions. Plant growth promotion activity of this strain of PGPR has resulted mainly in root length increase of seedlings and stress resistance of adult plants. In seedlings, we have seen a 1.3- to 1.8-fold increase in the root length over control plants with minimal increase in shoot length (Hontzeas et al. 2004; Li et al. 2000). Although measurement of the colonization of specific tissues was not performed here, only root-specific and not shoot colonization of the developing seedling after seed inoculation has been seen with free-living soil PGPR such as $P$. fluorescens (Chin-A-Woeng et al. 1997). Therefore, we suspect that the level of shoot colonization was minimal. That said, shoot-specific transcriptional activation of genes suggests systemic rhizobacterial effects of root colonization. This has also been suggested by a decrease in ACC seen in the xylem of plants in association with ACC deaminase-producing, rootcolonizing PGPR (Belimov et al. 2009), which would lead to reduced ethylene levels in areas of the plant distant from the direct location of bacterial colonization.

Plant expression profiling was used to investigate the plant's response to bacterial inoculation and, specifically, the response to the presence of bacterial ACC deaminase in order to illuminate some of the mechanisms involved in this enzyme's effect on plant growth. At the same time, the use of molecular tools designed for the study of Arabidopsis were investigated for their efficacy in studying a nonmodel organism like canola ( $B$. napus), for which sequence data and commercial microarrays are not yet available.

The profound effect on plant gene expression of bacterial inoculation (when compared with uninoculated control plants) was shared between plants inoculated with $\mathrm{ACD}^{+}$and $\mathrm{ACD}^{-} P$. putida UW4 and included changes in plant hormone transcription and secondary metabolism as well as several other metabolic pathways. Secondary metabolism, in particular, was highly downregulated, with multiple members in several pathways showing a significant decrease in transcription compared with control plants. In this regard, secondary metabolism functions to protect plants from a variety of stimuli including microbial attack (Bennett and Wallsgrove 1994) and is thought to be tightly controlled at the level of transcription of the biosynthesis genes (Vom Endt et al. 2002); hence, a decrease in the biosynthesis of several of these genes in the presence of plant growth-promoting bacteria suggests that a bacterial signal may be altering the plant's defense response.

Similarly, the induction of a stress response in plants inoculated with bacteria not producing ACC deaminase, in contrast to less stress-inducible transcription in plants inoculated with ACC deaminase-expressing bacteria, suggests both that plant growth-promoting bacteria can induce stress response transcription and that ACC deaminase may alleviate this response. The former conclusion was previously suggested by Timmusk and Wagner (1999), where a mild stress response, indicated by a slight upregulation of biotic stress response genes ATVSP, HEL, and PR-1, was observed in A. thaliana inoculated with the beneficial microorganism Paenibacillus polymyxa. In addition, the later conclusion has been shown experimentally with several ACC deaminase-producing bacterial strains and a variety of stresses (Glick 2004).

The upregulation of ARF transcription in the presence of bacterial ACC deaminase was of great interest because direct evidence of ethylene effects on auxin signaling is limited, likely due to the intimate interaction of these two developmentally important plant hormones (Stepanova et al. 2007). ARF belong to large families of genes known to be induced by active auxins; however, their role within the plant is not entirely understood. Two groups of genes were found to be upregulated within this study (AUX/IAA and SAUR); both are thought to be involved in regulating the auxin response directly and through an interaction with calcium and calmodulin (transcripts which were also found to be differentially regulated in the present study). The changes in ARF and calcium signal transcript abundance found here are evidence for bacterial-induced ethylene effects on auxin signaling in plants, an effect which suggests that a lowering of plant ethylene levels by $\mathrm{ACD}^{+}$bacteria may release repression of the auxin signaling cascade. According to the model described by Glick and associates (1999), IAA produced by the bacteria induces ACC synthase expression, which, in the absence of ACC deaminase, increases the level of ACC and, hence, ethylene in plant tissues. This ethylene may interact with plant auxinresponse signaling to repress bacterially induced auxin effects in the plant. Pseudomonas putida UW4 does produce IAA (Li et al. 2000), however, due to the presence of ACC deaminase, repression of auxin response appears to be lifted. In a complementary study, plant exudates were examined and the level of IAA exuded by the plant was dramatically increased in the presence of the wild-type bacterium whereas the mutant bacterium only increased IAA exudation slightly over the uninoculated plants (Cheng et al. 2009). Here, an increase in ARF expression was seen in plants in association only with ACC deaminase-expressing bacteria and not the $\mathrm{ACD}^{-}$mutant, suggesting that, in the absence of ethylene, ARF signaling can proceed, and that this may have an impact on plant IAA biosynthesis induction.

This study provides additional insight into the role of bacterial ACC deaminase in promoting plant growth and demonstrates the usefulness of molecular tools designed for the model plant A. thaliana for the study of nonmodel organisms from the Brassicaceae family such as canola.

Fig. 1. Hierarchical clustering of normalized intensity ratios. Blue boxes represent downregulation of a gene in the treatment versus the control and yellow boxes represent its upregulation. A, Expression change values for genes with greater than $\log _{2}=|0.5|$ (approximately 1.4 -fold change) in at least one treatment. B, C, and D, Enlarged areas of interest, where B and D show the co-expression of stress response genes (indicated by asterisks) and C shows the

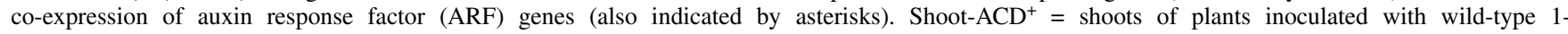
aminocyclopropane-1-carboxylic acid (ACC) deaminase-expressing Pseudomonas putida UW4. Shoot-ACD ${ }^{-}=$shoots of plants inoculated with ACC deaminase-minus mutant $P$. putida UW4; with a similar naming scheme used for root tissues. 


\section{MATERIALS AND METHODS}

\section{Plant growth conditions.}

This work was performed using B. napus var. Westar (canola). Prior to planting, all seeds were surface sterilized in $70 \%$ ethanol for $1 \mathrm{~min}$, then in $1 \%$ bleach for $10 \mathrm{~min}$, followed by several changes of sterile water. Seed were inoculated by soaking for $1 \mathrm{~h}$ in a bacterial suspension (optical density at $\left.600 \mathrm{~nm}\left[\mathrm{OD}_{600}\right]=0.5\right)$ in $0.05 \mathrm{M} \mathrm{MgSO}_{4}$ for treated seeds or with buffer alone for controls, then planted in vermiculite saturated with a hydroponic plant growth solution of $7 \%$ nitrogen, $11 \%$ phosphorous, and $27 \%$ potassium at a concentration of $0.63 \mathrm{~g} /$ liter and solution-grade calcium nitrate at a concentration of $0.43 \mathrm{~g} / \mathrm{liter}$ (Plant Products, Brampton, ON, Canada). In all, 40 seeds were planted per 9-in.-diameter pot and then placed inside a growth chamber with a constant

Table 1. Expression changes for each treatment organized by metabolic pathway ${ }^{\mathrm{a}}$

\begin{tabular}{|c|c|c|c|}
\hline Treatment & Gene name & $\mathrm{ACD}^{+}$-treated vs. control & $\mathrm{ACD}^{-}$-treated vs. control \\
\hline \multicolumn{4}{|l|}{ Phytohormones } \\
\hline Abscisic acid biosynthesis & AT5G67030 (ABA1) & -1.6 & $\ldots$ \\
\hline \multirow{2}{*}{ Ethylene biosynthesis } & AT1G05010 & 2.7 & 2.2 \\
\hline & AT2G30830 & -1.9 & \\
\hline \multirow[t]{3}{*}{ IAA biosynthesis } & AT4G39950 & $-1.5^{*}$ & $-1.5^{*}$ \\
\hline & AT5G22300 (NIT4) & -1.6 & $\ldots$ \\
\hline & AT5G20960 (AO1) & -1.6 & $\ldots$ \\
\hline \multirow[t]{2}{*}{ Jasmonic acid biosynthesis } & AT3G01420 & -1.6 & $\ldots$ \\
\hline & AT5G42650 (AOS) & $\ldots$ & 3.2 \\
\hline Phaseic acid biosynthesis & AT2G29090 (CYP707A2) & -2.6 & -2.3 \\
\hline \multirow[t]{2}{*}{ Salicylic acid biosynthesis } & AT3G53260 (PAL2) & -2.0 & -1.8 \\
\hline & AT2G37040 (PAL1) & -1.8 & -1.6 \\
\hline \multicolumn{4}{|l|}{ Photosynthesis } \\
\hline \multirow[t]{3}{*}{ Calvin cycle } & AT4G26520 & 1.8 & 2.1 \\
\hline & AT2G36460 & 1.5 & 1.9 \\
\hline & AT2G01140 & -2.3 & -1.9 \\
\hline Chlorophyll a degradation & AT4G37000 (RCCR) & 1.9 & 1.8 \\
\hline \multicolumn{4}{|l|}{ Carbohydrate metabolism } \\
\hline \multirow[t]{4}{*}{ Gluconeogenesis } & AT4G26520 & 1.7 & 2.1 \\
\hline & AT2G36460 & 1.5 & 1.9 \\
\hline & AT2G01140 & -2.3 & -1.9 \\
\hline & AT1G79530 (GapCp-1) & 1.5 & $\ldots$ \\
\hline \multirow[t]{7}{*}{ Glycolysis } & AT4G26520 & 1.7 & 2.1 \\
\hline & AT2G36460 & 1.5 & 1.9 \\
\hline & AT2G01140 & -2.3 & -1.9 \\
\hline & AT2G24270 (NP-GAPDH) & -2.4 & -1.9 \\
\hline & AT5G47810 & 2.4 & $\ldots$ \\
\hline & AT5G42740 & -1.3 & $\ldots$ \\
\hline & AT1G79530 (GapCp-1) & 1.5 & $\ldots$ \\
\hline \multirow[t]{3}{*}{ Lactose degradation } & AT3G52840 & 1.6 & 1.5 \\
\hline & AT5G63810 & 1.5 & $\ldots$ \\
\hline & AT1G45130 & 1.5 & $\ldots$ \\
\hline Mannose and mannitol degradation & AT3G02570 & $\ldots$ & 1.7 \\
\hline \multirow[t]{7}{*}{ Sucrose degradation } & AT4G26520 & 1.7 & 2.1 \\
\hline & AT2G36460 & 1.5 & 1.9 \\
\hline & AT2G01140 & -2.3 & -1.9 \\
\hline & AT5G47810 & 2.4 & $\ldots$ \\
\hline & AT1G79530 (GapCp-1) & 1.5 & $\ldots$ \\
\hline & AT5G20830 (SUS1) & 1.5 & $\ldots$ \\
\hline & AT3G43190 (SUS4) & 1.7 & $\ldots$ \\
\hline \multirow[t]{2}{*}{ Trehalose biosynthesis } & AT1G70290 (put TPS/TPP) & -1.8 & -1.7 \\
\hline & AT2G18700 (TPS11) & -1.9 & -2.4 \\
\hline \multicolumn{4}{|l|}{ Lipid metabolism } \\
\hline Choline biosynthesis & AT1G73600 & -5.5 & -3.4 \\
\hline \multirow{3}{*}{ Glycolipid desaturation } & AT5G05580 (FAD8) & -2.7 & -1.9 \\
\hline & AT3G15850 (FAD5) & -1.9 & $\ldots$ \\
\hline & AT3G11170 (FAD7) & -1.5 & $\ldots$ \\
\hline \multirow[t]{3}{*}{ Sterol biosynthesis } & AT5G24160 & -2.4 & -1.7 \\
\hline & AT5G24150 & -2.4 & -1.7 \\
\hline & AT4G37760 & -1.5 & -1.5 \\
\hline \multicolumn{4}{|l|}{ Cell walls } \\
\hline Cellulose biosynthesis & AT4G16590 & -6.2 & -2.8 \\
\hline & AT4G15290 & -2.5 & -1.9 \\
\hline & AT4G13410 & -3.1 & -2.3 \\
\hline & AT4G39350 & -1.5 & $\ldots$ \\
\hline & AT4G24000 & -1.6 & $\ldots$ \\
\hline & AT3G57260 & $\ldots$ & -1.6 \\
\hline & AT5G09870 & $\ldots$ & -1.5 \\
\hline Homogalacturonan degradation & AT1G60590 & -1.6 & -2.3 \\
\hline & AT3G49220 & $\ldots$ & -1.8 \\
\hline
\end{tabular}

${ }^{\text {a }}$ Fold change (in relation to untreated control) is reported for each gene in parentheses, with downregulation shown as a negative fold change. Entries followed by an asterisk are from plant roots and all others occurred in plant shoots. ACD ${ }^{+}$naturally expresses 1-aminocyclopropane-1-carboxylic acid (ACC) deaminase and $\mathrm{ACD}^{-}$is an $\mathrm{ACC}$ deaminase knockout mutant. 
temperature of $20^{\circ} \mathrm{C}$, a 12 -h photoperiod, and a light intensity of $50 \mu \mathrm{mol} \mathrm{m} \mathrm{m}^{-2} \mathrm{~s}^{-1}$ for 6 days. At the time of collection, seedlings did not have true leaves; however, cotyledons were dark green and they had developed secondary roots.

\section{Bacterial strains and growth conditions.}

The two bacterial strains used in this work were the ACC deaminase-producing strain $P$. putida $\mathrm{UW} 4\left(\mathrm{ACD}^{+}\right)$(Glick et al. 1995; Shah et al. 1998) and the ACC deaminase-minus mutant $P$. putida $\mathrm{UW} 4\left(\mathrm{ACD}^{-}\right)$, which has a tetracycline resistance gene inserted within the coding region of the ACC deaminase structural gene ( $\mathrm{Li}$ et al. 2000). The bacterial inoculum for the treatment of seed was prepared as follows. Tryptic soy broth (Becton, Dickinson and Company, Franklin Lakes, NJ, U.S.A.) was inoculated with frozen bacterial stock at $0.06 \%$ and then grown at $30^{\circ} \mathrm{C}$ for $16 \mathrm{~h}$. The culture was centrifuged at $8,000 \times g$ for $10 \mathrm{~min}$ at $4^{\circ} \mathrm{C}$ and then the cells were resuspended in $5 \mathrm{ml}$ of $0.05 \mathrm{M} \mathrm{MgSO}_{4}$. This wash-

Table 1. (continued from preceding page)

\begin{tabular}{|c|c|c|c|}
\hline Treatment & Gene name & $\mathrm{ACD}^{+}$-treated vs. control & $\mathrm{ACD}^{-}$-treated vs. control \\
\hline \multirow{4}{*}{ Starch degradation } & AT5G18670 & -1.8 & -1.5 \\
\hline & AT4G15210 & -1.7 & $\ldots$ \\
\hline & AT3G23920 & -1.8 & $\ldots$ \\
\hline & AT2G32290 & -2.0 & $\ldots$ \\
\hline \multirow[t]{4}{*}{ Suberin biosynthesis } & AT3G53260 (PAL2) & -2.0 & -2.0 \\
\hline & AT2G37040 (PAL1) & -1.8 & -1.8 \\
\hline & AT2G30490 (ATC4H) & -1.5 & $\ldots$ \\
\hline & AT5G54160 (OMT1) & -2.9 & $\ldots$ \\
\hline \multicolumn{4}{|l|}{ Nitrogen and sulfur metabolism } \\
\hline \multirow[t]{3}{*}{ Ammonia assimilation } & AT5G37600 (GLN1;1) & -2.3 & $\ldots$ \\
\hline & AT1G66200 (GLN1;2) & -2.2 & $\ldots$ \\
\hline & AT5G16570 (GLN1;4) & -1.9 & $\ldots$ \\
\hline \multirow[t]{2}{*}{ Cysteine biosynthesis } & AT1G55920 (SAT1) & -1.6 & $\ldots$ \\
\hline & AT3G13110 (SAT3) & -1.7 & $\ldots$ \\
\hline Methionine biosynthesis & AT3G03780 & -1.8 & $\ldots$ \\
\hline \multirow[t]{4}{*}{ Nitrate assimilation } & AT1G77760 (NIA1) & $\ldots$ & -1.5 \\
\hline & AT5G37600 (GLN1;1) & -2.3 & $\ldots$ \\
\hline & AT1G66200 (GLN1;2) & -2.2 & $\ldots$ \\
\hline & AT5G16570 (GLN1;4) & -1.9 & $\ldots$ \\
\hline \multirow[t]{4}{*}{ Sulfate reduction } & AT1G19920 (APS2) & -1.7 & -1.6 \\
\hline & AT3G22890 (APS1) & -2.5 & -2.0 \\
\hline & AT4G14680 (APR3) & -1.6 & -1.9 \\
\hline & AT1G62180 (APR2) & -2.1 & -2.3 \\
\hline \multicolumn{4}{|l|}{ Secondary metabolism } \\
\hline \multirow[t]{4}{*}{ Anthocyanin biosynthesis } & AT4G22880 & -1.8 & -1.9 \\
\hline & AT4G22870 & -2.9 & -2.5 \\
\hline & AT5G17050 & -1.9 & -1.8 \\
\hline & AT4G14090 & -1.5 & $\ldots$ \\
\hline Camalexin biosynthesis & AT4G39950 & $-1.5^{*}$ & $-1.5^{*}$ \\
\hline \multirow[t]{3}{*}{ Carotenoid biosynthesis } & AT4G25700 ( $\beta$-OHase1) & -1.9 & -1.8 \\
\hline & AT5G52570 ( $\beta$-OHase2) & -1.8 & -1.7 \\
\hline & AT5G67030 (ABA1) & -1.6 & $\ldots$ \\
\hline \multirow[t]{3}{*}{ Flavonoid biosynthesis } & AT5G13930 & -5.1 & -4.5 \\
\hline & AT3G51240 & -2.3 & -2.0 \\
\hline & AT1G20510 & $\ldots$ & 1.8 \\
\hline \multirow[t]{2}{*}{ Flavonol biosynthesis } & AT5G08640 (FLS) & -2.0 & -1.5 \\
\hline & AT5G54160 (OMT1) & -2.9 & $\ldots$ \\
\hline \multirow[t]{2}{*}{ Geranyldiphosphate biosynthesis } & AT1G78510 (SPS1) & -2.1 & -1.8 \\
\hline & AT1G17050 (SPS2) & -1.7 & $\ldots$ \\
\hline \multirow[t]{2}{*}{ Glucosinolate biosynthesis } & AT4G39950 & $-1.5^{*}$ & $-1.5^{*}$ \\
\hline & AT4G13770 & -1.7 & $\ldots$ \\
\hline \multirow[t]{2}{*}{ Glucosinolate breakdown } & AT1G54040 & 1.6 & 1.6 \\
\hline & AT5G22300 & -1.6 & $\ldots$ \\
\hline Kaempferol glucoside biosynthesis & AT5G54060 & -1.9 & -1.8 \\
\hline & AT4G01070 & -1.7 & $\ldots$ \\
\hline Phenylpropanoid biosynthesis & AT3G53260 (PAL2) & -2.0 & -1.8 \\
\hline & AT2G37040 (PAL1) & -1.8 & -1.6 \\
\hline & AT1G09500 & -2.5 & -1.9 \\
\hline & AT1G20510 & $\ldots$ & 1.8 \\
\hline & AT2G30490 (ATC4H) & -1.5 & $\ldots$ \\
\hline & AT1G09510 & -1.6 & $\ldots$ \\
\hline & AT4G36220 & -2.0 & $\ldots$ \\
\hline Response to stress & & & \\
\hline Glutamate degradation & AT1G65960 & 3.5 & 2.7 \\
\hline & AT3G22200 (POP2) & 1.8 & 1.8 \\
\hline & AT1G79440 & 1.7 & 1.6 \\
\hline Removal of superoxide radicals & AT1G08830 (CSD1) & -1.6 & $-2.0,-1.5^{*}$ \\
\hline & AT4G25100 (FSD1) & $\ldots$ & $1.6,1.6^{*}$ \\
\hline Other & & & \\
\hline Cyanate degradation & AT5G14740 (CA2) & -3.3 & -4.0 \\
\hline & AT3G52720 & -1.7 & -1.6 \\
\hline & AT1G70410 & -1.5 & $\ldots$ \\
\hline & AT3G01500 (CA1) & $\ldots$ & $1.8^{*}$ \\
\hline
\end{tabular}


ing step was repeated and the final pellet was suspended in enough $0.05 \mathrm{M} \mathrm{MgSO}_{4}$ to obtain a final $\mathrm{OD}_{600}$ of 0.5 .

\section{RNA isolation.}

Plant tissues (roots and shoots) were separated, placed directly into liquid nitrogen, and then stored at $-80^{\circ} \mathrm{C}$ until needed. Total RNA was isolated as described by Davis and associates (1986) as follows. Frozen tissue was homogenized to a fine powder with a mortar and pestle with liquid nitrogen and total RNA extracted in $10 \mathrm{ml}$ of buffer (4 M guanidine isothiocyanate, $3 \mathrm{M}$ sodium acetate [pH 6.0], and $8.35 \mu \mathrm{l}$ of $\beta$ mercaptoethanol per milliliter of buffer). The mixture was passed through MiraCloth (Calbiochem, San Diego, CA, U.S.A.) to remove plant material, then centrifuged at $30,000 \times$ $g$ and $4{ }^{\circ} \mathrm{C}$ for 15 min to pellet cellular debris. The supernatant was layered onto $3.3 \mathrm{ml}$ of $5.7 \mathrm{M} \mathrm{CsCl}$, then centrifuged at $116,000 \times g$ and $10^{\circ} \mathrm{C}$ for $23 \mathrm{~h}$. The liquid in the tube was removed and the RNA pellet was washed with $70 \%$ ethanol and suspended in $500 \mu \mathrm{l}$ of $0.5 \mathrm{M}$ sodium acetate, $\mathrm{pH}$ 5.5. RNA was precipitated with ice-cold $100 \%$ ethanol, held at $-80^{\circ} \mathrm{C}$ for at least $1 \mathrm{~h}$, then centrifuged for $1 \mathrm{~h}$ at $20,000 \times g$ and $4^{\circ} \mathrm{C}$ in a microcentrifuge. The pellet was washed with $1 \mathrm{ml}$ of $70 \%$ ethanol and centrifuged at $20,000 \times g$ and $4^{\circ} \mathrm{C}$ for $30 \mathrm{~min}$ before the supernatant was removed and the pellet was dried and resuspended in water. Quantitation was performed by spectrophotometry and RNA samples used for microarray analysis were further purified using the Qiagen RNeasy Midi kit (Valencia, CA, U.S.A.), then stored at $-80^{\circ} \mathrm{C}$ until needed. Upon thawing, the integrity of RNA samples was determined by denaturing formaldehyde gel electrophoresis.

\section{Microarray experiments.}

Seedlings inoculated with bacteria $\left(\mathrm{ACD}^{+}\right.$or $\mathrm{ACD}^{-}$P. putida UW4) were compared with matching untreated control tissue in two-color microarray hybridizations performed in triplicate (from three separate experiments of 40 seedlings each, with individual RNA isolations), where roots and shoots were processed separately. Targets were generated from mRNA using a fluorescent direct label kit (Agilent Technologies, Santa Clara, CA, U.S.A.) with cyanine-3- and cyanine-5-labeled dCTPs (Perkin Elmer, Waltham, MA, U.S.A.). A. thaliana oligonucleotide microarrays were used that contained approximately 28,000

Table 2. Genes in Arabidopsis corresponding to real-time reverse-transcriptase polymerase chain reaction (RT-PCR) targets in Brassica spp. ${ }^{\text {a }}$

\begin{tabular}{|c|c|c|c|c|c|}
\hline TAIR ID ID $^{b}$ & Description & $\begin{array}{l}\text { Arabidopsis } \\
\text { Ref_sequence }\end{array}$ & $\begin{array}{l}\text { Brassica } \\
\text { EST }^{c}\end{array}$ & $\begin{array}{l}\text { Identity } \\
(\%)^{\mathrm{d}}\end{array}$ & $\begin{array}{l}\text { Expected } \\
\text { value }^{\mathrm{e}}\end{array}$ \\
\hline AT5G42650 & Allene oxide synthase (AOS) & NM_123629 & RL2795* & 87 & $4.00 \mathrm{E}-28$ \\
\hline AT3G15540 & Auxin response transcription factor (IAA19) & NM_112422 & CD1204* & 84 & $8.00 \mathrm{E}-39$ \\
\hline AT2G14610 & Pathogenesis-related 1 (PR1) & NM_127025 & OL6017* & 84 & $1.00 \mathrm{E}-37$ \\
\hline AT4G25100 & Fe superoxide dismutase 1 (FSD1) & NM_179110 & OL8300* & 87 & $9.00 \mathrm{E}-22$ \\
\hline AT2G43910 & Thiol methyltransferase (TMT) & NM_129953 & LR2697* & 86 & $2.00 \mathrm{E}-38$ \\
\hline AT5G07580 & Ethylene response factor (ERF) & NM_120840 & OL6713* & 88 & $2.00 \mathrm{E}-38$ \\
\hline AT3G58680 & Ethylene-responsive transcriptional co-activator (ERTC) & NM_115730 & DC895* & 86 & $9.00 \mathrm{E}-30$ \\
\hline AT1G05010 & 1-aminocyclopropane-1-carboxylate oxidase (ACO) & NM_100380 & DL1563* & 90 & $3.00 \mathrm{E}-72$ \\
\hline AT1G70940 & Auxin transport protein (PIN3) & NM_105762 & AJ249298 & 78 & $4.00 \mathrm{E}-44$ \\
\hline
\end{tabular}

a Percent identity of nucleotides and $E$ values are based on Blastn results for real-time RT-PCR products.

b The Arabidopsis Information Resource (TAIR) accession number.

${ }^{\mathrm{c}} \mathrm{EST}=$ expressed-sequence tag. Asterisks denote sequences that do not appear in GenBank.

${ }^{\mathrm{d}}$ Identity of alignment between the sequenced RT-PCR product (which matched the Brassica sequence with $98 \%$ identity) and the Arabidopsis reference sequence.

e Expected value of Arabidopsis reference sequence to sequenced RT-PCR products.
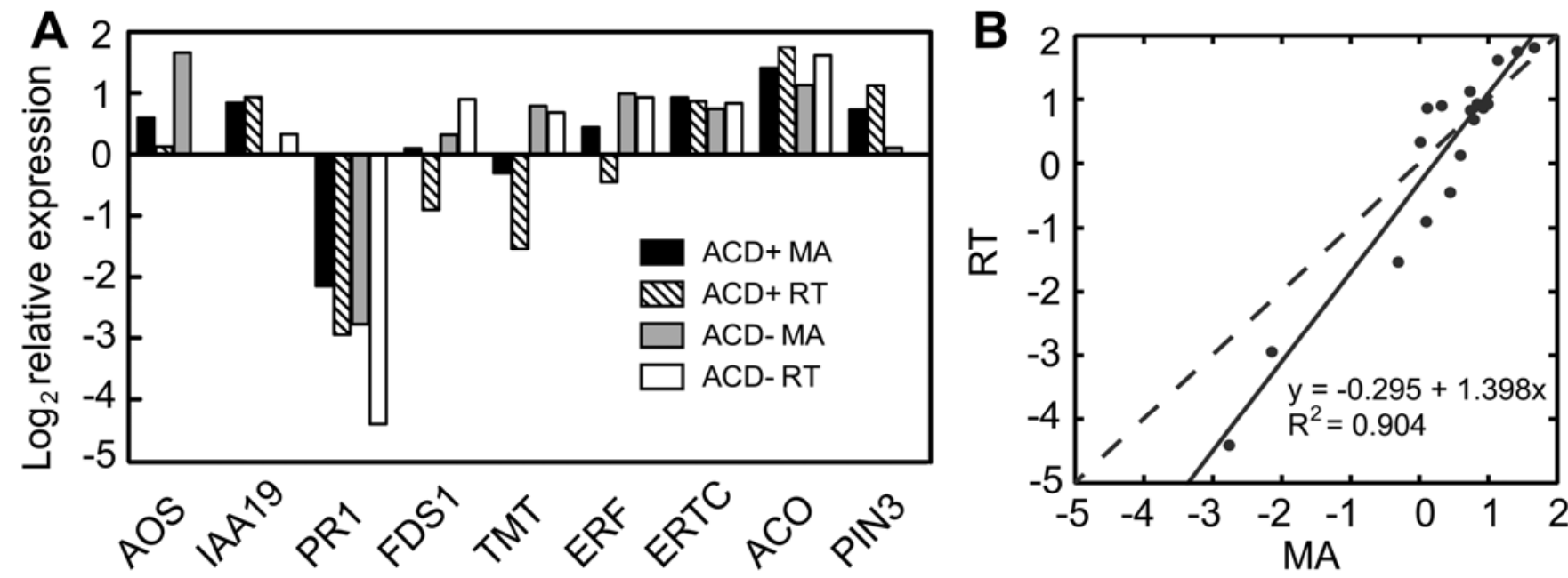

Fig. 2. A, Relative expression $\left(\log _{2}\right)$ between treated and control tissues for selected genes. The small amount of error between replicate experiments caused the error bars in (representing SEM) to be very small and difficult to see. B, Correlation of the values measured with real-time reverse-transcriptase polymerase chain reaction (RT) and the microarray (MA); the solid line and the equation indicate the regression calculated for the data whereas the dotted line indicates a 1:1 relationship line and illustrates that the magnitude of the fold changes measured with RT was larger than MA because most of the positive fold changes appear above the 1:1 line and many negative fold changes appear below it. ACD ${ }^{+}=$plants inoculated with wild-type Pseudomonas putida $\mathrm{UW}_{4}$ that express a functional 1-aminocyclopropane-1-carboxylic acid (ACC) deaminase gene; ACD $^{-}=$plants inoculated with ACC deaminase-minus mutant of the same strain; AOS = allene oxide synthase; IAA19 = auxin response transcription factor; PR1 = pathogenesis-related 1; FSD1 = Fe superoxide dismutase 1 ; TMT $=$ thiol methyltransferase; ERF = ethylene response factor; ERTC $=$ ethylene-responsive transcriptional co-activator; ACO = 1-aminocyclopropane1-carboxylate oxidase; PIN3 = auxin transport protein. 
60-nt probes for the coding region of genes representing $80 \%$ of the genome. Arrays and all hybridization reagents were purchased from Agilent Technologies, and all steps carried out as recommended in the Agilent Oligo Microarray Kit Hybridization Protocol (v 5.0). Scanning was performed with a GenePix Professional 4200A scanner (Molecular Devices, Sunnyvale, CA, U.S.A.) with software v 6.0. Due the range of spot intensities for shoots, two scans per slide were carried forward to increase the robustness of the normalization correction, whereas one scan per slide was used for roots.

\section{Data analysis.}

Background correction and normalization was performed as follows where data for roots and shoots were analyzed separately. Raw data were imported into the $\mathrm{R}$ environment $\mathrm{v}$ 2.5.0 and analyzed using the LIMMA library (Linear Models for Microarray Data, v 2.10.5) (Smyth 2004) of the bioconductor package (Gentleman et al. 2004). Because background values were uniform and low, pure subtraction of background intensity values from the foreground intensity values was used. LOESS normalization was used to correct for within-array dye and spatial effects then these values were quantile normalized across arrays (Smyth 2004). The two replicate scans per slide (for shoots only) were used to maximize the robustness of each gene's differential expression measurement via the $1 \mathrm{mFit}$ function within LIMMA. This step uses a pooled correlation estimate to generate a more robust estimate of gene expression across replicates, compared with a straight average of replicates. Moderated $t$ statistics were computed for each gene based on an empirical Bayes method (Smyth 2004), which shrinks the standard errors toward a common value. Raw and normalized data was deposited in the National Center for Biotechnology Information microarray database Gene Expression Omnibus with the accession number GSE31396.

False discovery rate adjustment of $P$ values was performed using the Benjamini and Hochberg multiple testing procedure (Benjamini and Hochberg 1995). An approximate fold change cut-off of 1.4 was used which was approximately equal to a $P$ $<0.05$ for all treatments compared with controls except for $\mathrm{ACD}^{-}$-treated roots, where it was equal to $P=0.0253$.

\section{Clustering.}

For cluster analysis, an average was taken across all three replicates for the expression change value of each gene and a cut-off of greater than $\log _{2}=|0.5|$, approximately 1.4-fold change, in at least one treatment was used for normalized intensity ratios. Clustering of the resulting 850 genes was performed using Cluster v 3.0 for Mac OS X (C Clustering Library 1.36)
(Eisen et al. 1998) using centered correlation and centroid linkage parameters, where genes and arrays were clustered based on similarity. The cluster diagram was made with Java TreeView v 1.1.1 (Saldanha 2004).

\section{Assignment of biological context.}

Functional categorization was performed using only genes with statistically significant expression changes. Genes were assigned to metabolic pathways with the use of the Pathway Tools v 14.0 Omics Viewer and the AraCyc database v 7. This release contained 283 pathways with 1,901 unique genes assigned to pathways, $90 \%$ of which were experimentally confirmed. The Pathways Tool Omics Viewer was used to paint microarray data onto the metabolic overview diagram for Arabidopsis and to assign individual genes and their expression changes to individual metabolic pathways.

\section{Microarray validation.}

In order to quantify transcript levels of $B$. napus genes, which showed differential expression on the A. thaliana microarray, real-time RT-PCR was used. Nine genes were chosen from those in the list of statistically significant changes and the sequence of the corresponding probe from the microarray (60 bases) was used to query the Brassica EST database, which is housed at the Saskatoon Research Center (Molecular Genetics Section, Agriculture and Agri-Food Canada, Saskatoon). This database contained sequences from 31 Brassica EST libraries comprising 148,956 sequences and 84,143,936 total letters. The best EST for each gene was aligned with the microarray probe sequence using the ClustalW multiple sequence alignment web tool and primers were designed to amplify the region of overlap between the Brassica EST sequence and the microarray probe sequence (Table 3). Following primer optimization, RT-PCR products were visualized using a $4 \%$ agarose gel and only primer sets that amplified a single band were carried forward. RT-PCR products were sequenced and used to query the GenBank nucleotide collection (nr/nt) for the Brassicaceae family (organism taxid:3700) using the BLASTN algorithm. In every case, the $A$. thaliana reference sequence for the gene of interest matched the RT-PCR product with high identity (Table 2).

Real-time RT-PCR was performed as follows. RNA (1 $\mu \mathrm{g})$ from each sample was reverse transcribed in a $20-\mu$ l volume using Superscript III (Invitrogen, Carlsbad, CA U.S.A.) with oligodT17 primers at a concentration of $1 \mu \mathrm{M}$ (Sigma-Aldrich, St. Louis), then treated with RNAse H (Ambion, Foster City, CA, U.S.A.). cDNA $(2 \mu \mathrm{l})$ was PCR amplified with iScript master mix containing SYBR green (Bio-Rad, Hercules, CA,

Table 3. Primer sequences used for real-time reverse-transcriptase polymerase chain reaction ${ }^{\mathrm{a}}$

\begin{tabular}{|c|c|c|c|c|}
\hline $\begin{array}{l}\text { Brassica } \\
\text { EST }^{\mathbf{b}}\end{array}$ & Forward primer & Reverse primer & $\begin{array}{c}\text { Product } \\
\text { length (bp) }\end{array}$ & Description \\
\hline RL2795* & AATAAACAGTGCGCCGGTAAGGAC & TGAATGTAACGGagcttcccaacg & 130 & Allene oxide synthase (AOS) \\
\hline CD1204* & CGACACCGCTTTCACATTGATCAC & TGGACTCGGGCTTGAGATAACTGA & 134 & $\begin{array}{l}\text { Auxin response transcription factor } \\
\text { (IAA19) }\end{array}$ \\
\hline OL6017* & TCCCCGAGGATCATAGTTGCAAGA & ACTACGCTTCGAACACGTGCAT & 143 & Pathogenesis-related 1 (PR1) \\
\hline OL8300* & ATTGACGTCTGGGAGCATGCTTAC & GCAGCGTGAAGTCTGGAACTAACA & 119 & Fe superoxide dismutase 1 (FSD1) \\
\hline LR2697* & TGTGCCATTGAGCCTGAGATGAG & cctacgggaaccaaaacatcttcg & 167 & Thiol methyltransferase (TMT) \\
\hline OL6713* & TGACTGTGCAGCTTTCAAGCTC & gacgatgaagatgaattgctctgac & 159 & Ethylene response factor (ERF) \\
\hline DC895* & catgaacgtgtgcctactgagttg & TCGGTATTGCTTTCCCAGACTCGT & 142 & $\begin{array}{l}\text { Ethylene-responsive transcriptional } \\
\text { coactivator (ERTC) }\end{array}$ \\
\hline DL1563* & ATAGCTCAAACGGACGGAGAAGG & ttggccacagttgtctccatagc & 214 & $\begin{array}{l}\text { 1-Aminocyclopropane-1-carboxylate } \\
\text { oxidase (ACO) }\end{array}$ \\
\hline AJ249298 & GAGGGAGAAGGAAGACGAGAATGT & TCTCGTTGCCCCATGTTTTGCT & 208 & Auxin transport protein (PIN3) \\
\hline AF044573 & TTGGGATGAACCAGAAGGACG & GCTCGTTGTAGAAAGTGTGATGCC & 147 & Brassica oleracea actin (Act1) \\
\hline
\end{tabular}

\footnotetext{
${ }^{a}$ Lowercase letters denote where the primers overlapped with the probe binding site.

${ }^{b}$ Asterisks denote Brassica expressed sequence tag (EST) sequences from the Brassica EST database at the Saskatoon Research Center (Molecular Genetics Section, Agriculture and Agri-Food Canada) that do not appear in GenBank.
} 
U.S.A.) in a $20-\mu \mathrm{l}$ reaction volume with $500 \mathrm{nM}$ both the forward and reverse primers (Sigma-Aldrich) and the reactions were done in duplicate. PCR was performed using a Bio-Rad MiniOpticon thermal cycler with the following parameters: denaturation for $10 \mathrm{~s}$ at $95^{\circ} \mathrm{C}$, annealing for $20 \mathrm{~s}$ at $62^{\circ} \mathrm{C}$, and extension for $20 \mathrm{~s}$ at $72^{\circ} \mathrm{C}$ for 40 cycles, followed by a melting curve measured in $0.5^{\circ} \mathrm{C}$ increments, used to evaluate product purity. Actin 1 (AF044573) from B. oleracea was used as the reference gene and calculations of relative transcript abundance were calculated using the Livak method (Livak and Schmittgen 2001), where treatments included bacterially treated tissues (both $\mathrm{ACD}^{+}$and $\mathrm{ACD}^{-}$) and controls were matching uninoculated tissues. Experiments were done in triplicate with mRNA from separate isolations.

\section{ACKNOWLEDGMENTS}

We thank M. Gruber at Agriculture and Agri-Food Canada for providing us with access to the Brassica EST library. The Natural Sciences and Engineering Research Council of Canada provided the funding for this study.

\section{LITERATURE CITED}

Abeles, F. B., Morgan, P. W., and Saltveit, M. E. 1992. Ethylene in plant biology. Academic Press, New York.

Belimov, A., Dodd, I. C., Hontzeas, N., Theobald, J. C., Safronova, V. I., and Davies, W. J. 2009. The rhizosphere bacterium Variovorax paradoxus 5C-2 containing ACC deaminase does not increase systemic ABA signaling in maize (Zea mays L.). New Phytol. 181:413-423.

Benjamini, Y., and Hochberg, Y. 1995. Controlling the false discovery rate: A practical and powerful approach to multiple testing. J. Roy. Stat. Soc. Ser. B 57:289-300.

Bennett, R. N., and Wallsgrove, R. M. 1994. Tansley Review No. 72. Secondary metabolites in plant defense mechanisms. New Phytol. 127:617-633.

Bleecker, A. B., and Kende, H. 2000. Ethylene: A gaseous signal molecule in plants. Annu. Rev. Cell Dev. Biol. 16:1-18.

Brady, S. M., Orlando, D. A. Lee, J., Wang, J. Y., Koch, J., Dinneny, J. R., Mace, D., Ohler, U., and Benfey, P. N. 2007. A high-resolution root spatiotemporal map reveals dominant expression patterns. Science 318:801-806

Cheng, Z., Park, E., and Glick, B. R. 2007. 1-aminocyclopropane-1-carboxylate deaminase from Pseudomonas putida UW4 facilitates the growth of canola in the presence of salt. Can. J. Microbiol. 53:912-918.

Cheng, Z., Duan, J., Hao, Y., McConkey, B. J., and Glick, B. R. 2009. Identification of bacterial proteins mediating the interactions between Pseudomonas putida UW4 and Brassica napus (Canola). Mol. PlantMicrobe Interact. 22:686-694.

Chin-A-Woeng, T. F. C., dePriester, W., vanderBij, A. J., and Lugtenberg, B. J. J. 1997. Description of the colonization of a gnotobiotic tomato rhizosphere by Pseudomonas fluorescens biocontrol strain WCS365, using scanning electron microscopy. Mol. Plant-Microbe Interact. 10:79-86.

Davis, L. G., Dibner, M. D., and Battey, J. B. 1986. Preparation and analysis of RNA from eukaryotic cells. In: Basic Methods in Molecular Biology. Elsevier Science Publishing Co., Inc., New York.

Eisen, M. B., Spellman, P. T., Brown, P. O., and Botstein, D. 1998. Cluster analysis and display of genome-wide expression patterns. Proc. Natl. Acad. Sci. U.S.A. 95:14863-14868.

Farwell, A. J., Vesely, S., Nero, V., Rodriguez, H., McCormack, K., Shah, S., Dixon, D. G., and Glick, B. R. 2007. Tolerance of transgenic canola plants (Brassica napus) amended with plant growth-promoting bacteria to flooding stress at a metal-contaminated field site. Environ. Pollut. 147:540-545.

Gentleman, R. C., Carey, V. J., Bates, D. M., Bolstad, B., Dettling, M., Dudoit, S., Ellis, B., Gautier, L., Ge, Y., Gentry, J., Hornik, K., Hothorn, T., Huber, W., Iacus, S., Irizarry, R., Leisch, F., Li, C., Maechler, M., Rossini, A. J., Sawitzki, G., Smith, C., Smyth, G., Tierney, L., Yang, J. Y., and Zhang, J. 2004. Bioconductor: Open software development for computational biology and bioinformatics. Genome Biol. 5:R80.81R80.16.

Glick, B., Cheng, Z., Czarny, J., and Duan, J. 2007. Promotion of plant growth by ACC deaminase-producing soil bacteria. Eur. J. Plant Pathol. 119:329-339.

Glick, B. R. 2003. Phytoremediation: Synergistic use of plants and bacteria to clean up the environment. Biotechnol. Adv. 21:383-393.

Glick, B. R. 2004. Bacterial ACC deaminase and the alleviation of plant stress. Adv. Appl. Microbiol. 56:291-312.

Glick, B. R., Karaturovic, D. M., and Newell, P. C. 1995. A novel procedure for rapid isolation of plant growth promoting pseudomonads. Can. J. Microbiol. 41:533.

Glick, B. R., Patten, C. L., Holguin, G., and Penrose, D. M. 1999. Biochemical and Genetic Mechanisms Used by Plant Growth Promoting Bacteria. Imperial College Press, London.

Hagen, G., and Guilfoyle, T. 2002. Auxin-responsive gene expression: Genes, promoters and regulatory factors. Plant Mol. Biol. 49:373-385

Hontzeas, N., Saleh, S. S., and Glick, B. R. 2004. Changes in gene expression in canola roots induced by ACC-deaminase-containing plantgrowth-promoting bacteria. Mol. Plant-Microbe Interact. 17:865-871.

Hyodo, H. 1991. Stress/wound ethylene. In: The Plant Hormone Ethylene. A. K. Mattoo and J. C. Suttle, eds. CRC Press, Boca Raton, FL, U.S.A.

Kloepper, J. W., Lifshitz, R., and Zablotowicz, R. M. 1989. Free-living bacterial inocula for enhancing crop productivity. Trends Biotechnol. 7:39-44.

Li, J., Ovakim, D. H., Charles, T. C., and Glick, B. R. 2000. An ACC deaminase minus mutant of Enterobacter cloacae UW4 no longer promotes root elongation. Curr. Microbiol. 41:101-105.

Livak, K. J., and Schmittgen, T. D. 2001. Analysis of relative gene expression data using real-time quantitative PCR and the 2(-Delta Delta C(t)) method. Methods 25:402-408.

Lugtenberg, B., and Kamilova, F. (2009). Plant-growth-promoting rhizobacteria. Annu. Rev. Microbiol. 63:541-556.

Madhaiyan, M., Poonguzhali, S., Ryu, J., and Sa, T. 2006. Regulation of ethylene levels in canola (Brassica campestris) by 1-aminocyclopropane-1-carboxylate deaminase-containing Methylobacterium fujisawaense. Planta 224:268-278.

Penrose, D. M., Moffatt, B. A., and Glick, B. R. 2001. Determination of 1aminocycopropane-1-carboxylic acid (ACC) to assess the effects of ACC deaminase-containing bacteria on roots of canola seedlings. Can. J. Microbiol. 47:77-80

Reed, M. L. E., and Glick, B. R. 2004. Applications of free living plant growth-promoting rhizobacteria. Antonie Leeuwenhoek 86:1-25.

Saldanha, A. J. 2004. Java Treeview-extensible visualization of microarray data. Bioinformatics 20:3246-3248.

Shah, S., Li, J., Moffatt, B. A., and Glick, B. R. 1998. Isolation and characterization of ACC deaminase genes from two different plant growthpromoting rhizobacteria. Can. J. Microbiol. 44:833.

Smyth, G. K. 2004. Linear models and empirical Bayes methods for assessing differential expression in microarray experiments. Stat. Appl. Genet. Mol. Biol. 3:Article3.

Stepanova, A. N., Yun, J., Likhacheva, A. V., and Alonso, J. M. 2007. Multilevel interactions between ethylene and auxin in Arabidopsis roots. Plant Cell 19:2169-2185.

Timmusk, S., and Wagner, E. G. 1999. The plant-growth-promoting rhizobacterium Paenibacillus polymyxa induces changes in Arabidopsis thaliana gene expression: A possible connection between biotic and abiotic stress responses. Mol. Plant-Microbe Interact. 12:951-959.

Vom Endt, D. Kijne, J. W., and Memelink, J. 2002. Transcription factors controlling plant secondary metabolism: What regulates the regulators? Phytochemistry 61:107-114.

Walker, T. S., Bais, H. P., Grotewold, E., and Vivanco, J. M. 2003. Root exudation and rhizosphere biology. Plant Physiol. 132:44-51

Zhang, P., Foerster, H., Tissier, C., Mueller, L., Paley, S., Karp, P., and Rhee, S. Y. 2005. MetaCyc and AraCyc. Metabolic pathway databases for plant research. Plant Physiol. 138:27-37.

\section{AUTHOR-RECOMMENDED INTERNET RESOURCES}

Agriculture and Agri-Food Canada: www.agr.gc.ca

The Arabidopsis information resource: www.arabidopsis.org

BLAST, Basic local alignment search tool: www.ncbi.nlm.nih.gov/blast/Blast.cgi

ClustalW multiple sequence alignment tool: http://www.ebi.ac.uk/Tools/clustalw

Cluster 3.0, Open source clustering software: bonsai.ims.u-tokyo.ac.jp/ mdehoon/software/cluster/index.html

EMBL-EBI ArrayExpress: www.ebi.ac.uk/aerep/login

Fatigo: bioinfo.cipf.es/babelomicswiki/tool:fatigo

Jalview multiple alignment viewer: www.jalview.org

Java TreeView, gene expression visualization tool:

jtreeview.sourceforge.net

Pathway Tools Omics Viewer: biocyc.org/expression.html

The R Project for Statistical Computing: www.r-project.org

National Center for Biotechnology Information Gene Expression Omnibus: www.ncbi.nlm.nih.gov/geo/query/acc.cgi?token=hjkfbcoqissaezc\&acc= GSE31396 